\title{
Identification of serum proteins and multivariate models for diagnosis and therapeutic monitoring of lung cancer
}

\author{
Rong $\mathrm{Ma}^{1}$, Heng $\mathrm{Xu}^{2}$, Jianzhong $\mathrm{Wu}^{1}$, Ashok Sharma ${ }^{3}$, Shan $\mathrm{Bai}^{3}$, Boying Dun ${ }^{3}$, \\ Changwen Jing ${ }^{1}$, Haixia $\mathrm{CaO}^{1}$, Zhuo Wang ${ }^{1}$, Jin-Xiong She ${ }^{3}$, Jifeng Feng ${ }^{1}$ \\ ${ }^{1}$ Clinical Cancer Research Center, Jiangsu Cancer Hospital, Nanjing Medical University Affiliated Cancer Hospital Cancer \\ Institute of Jiangsu Province, Nanjing, Jiangsu, 210009, China \\ ${ }^{2}$ Jiangsu Province Institute of Materia Medica, Nanjing Tech University, Nanjing, 211816, China \\ ${ }^{3}$ Center for Biotechnology and Genomic Medicine, and Department of Obstetrics and Gynecology, Medical College of Georgia, \\ Augusta University, Augusta, GA, 30912, USA
}

Correspondence to: Jifeng Feng, email: fjif@vip.sina.com

Keywords: tumor antigens, NSCLC, inflammation, biomarkers, therapeutic response

Received: July 07, $2016 \quad$ Accepted: December 27, $2016 \quad$ Published: January 21, 2017

\section{ABSTRACT}

Lung cancer is one of the most prevalent cancers and has very poor treatment outcome. Biomarkers useful for screening and assessing early therapeutic response may significantly improve the therapeutic outcome but are still lacking. In this study, serum samples from 218 non-small cell lung cancer (NSCLC) patients, 34 small cell lung cancer (SCLC) patients and 171 matched healthy controls from China were analyzed for 11 proteins using the Luminex multiplex assay. Eight of the 11 proteins (OPN, SAA, CRP, CYFRA21.1, CEA, NSE, AGP and HGF) are significantly elevated in NSCLC and SCLC $\left(p=10^{-5}-10^{-59}\right)$. At the individual protein level, OPN has the best diagnostic value for NSCLC (AUC $=0.92$ ), two acute phase proteins (SAA and CRP) have AUC near 0.83, while CEA and CYFRA21.1 also possess good AUC (0.81 and 0.77, respectively). More importantly, several three-protein combinations that contain OPN and CEA plus one of four proteins (CRP, SAA, CYFRA21.1 or NSE) have excellent diagnostic potential for NSCLC (AUC $=0.96)$. Four proteins (CYFRA21.1, CRP, SAA and NSE) are severely reduced and three proteins (OPN, MIF and NSE) are moderately decreased after platinum-based chemotherapy. Therapeutic response index (TRI) computed with 3-5 proteins suggests that approximately $25 \%$ of the NSCLC patients respond well to the therapy and TRI is significantly correlated with pre-treatment protein levels. Our data suggest that therapeutic response in NSCLC patients can be effectively measured but personalized biomarkers may be needed to monitor different subsets of patients.

\section{INTRODUCTION}

Lung cancer (LC) has a 5-year survival rate of approximately $15 \%$ and is one of the leading causes of all cancer-related deaths worldwide [1]. Although there has been improvement in early detection and treatment, the prognosis is still poor for lung cancer patients $[2,3]$. Biomarkers that allow early diagnosis, guidance of therapeutic selection and/or early assessment of therapeutic outcome should improve care for lung cancer patients. Several widely known cancer antigens including cytokeratin 19 fragment (CYFRA21-1), carcinoembryonic antigen (CEA), neuron-specific enolase (NSE) have been found elevated in some lung cancer patients [4-7].
Chronic inflammation plays an important role in tumorigenesis. Inflammatory proteins may be increased by tumor growth which induces an inflammatory microenvironment $[8,9]$. Thus, inflammatory proteins can potentially serve as biomarkers for cancer diagnosis, prognosis and recurrence. Various types of cancers have been associated with serum amyloid A (SAA), C-reactive protein (CRP) and $\alpha 1$-acid glycoprotein (AGP). These non-specific, acute-phase proteins are secreted in response to various cytokines including IL-1, IL-6 and TNF- $\alpha$ [10-12]. SAA and CRP are elevated in the serum of various cancers [13-18] including lung cancer [19, 20]. Both SAA and CRP also possess some prognostic potential for predicting survival of lung cancer patients 
$[19,20]$. However, these proteins are elevated in a variety of disease conditions and are not sufficient for diagnostic or prognostic purposes by themselves.

Osteopontin (OPN) plays a critical role in many biological processes including tumor progression, metastasis and angiogenesis. OPN in the serum is elevated in different types of cancers [21-24] including lung cancer $[25,26]$ and patients with high serum OPN have poor survival [25-27]. Just like the other biomarkers discussed above, OPN by itself is not sufficient for clinical application.

Serum migration inhibitory factor (MIF) has been assessed as biomarker for lung cancer [28]. Hepatocyte growth factor (HGF) was found to be increased [29-31] in the serum of patients with lung cancer and high levels of serum HGF may be associated with poor survival [32]. However, another study found decreased serum HGF levels in lung cancer patients [33]. Serum E-Selectin was reported to be elevated in lung cancer patients $[34,35]$. Growth-related oncogene (GRO) is expressed in many types of tumors. Serum GRO was found to be elevated in stage IV gastric cancer patients [36] although it has not been studied in lung cancer. A number of studies also attempted to discover combinations of serum proteins to achieve better diagnostic or prognostic value [7, 36-38]. Despite of improvement over single molecules, none of the reported combinations achieved sufficiently high specificity and sensitivity.

Assessing the therapeutic response soon after initiation of treatment is potentially of great importance to improve care for lung cancer patients. On one hand, stopping unsuccessful treatment can allow patients to consider different treatment options and on the other hand it avoids unnecessary side effects caused by unresponsive therapies. Biomarkers measured both before treatment or soon after treatment may be used for this purpose and have been target for development for many cancers [36, 39-41] and in limited studies for lung cancer [42-44]. However, clinically actionable biomarkers have yet to be developed.

In this study, we analyzed eleven serum proteins in a large panel of NSCLC patients and healthy controls as well as a small number of SCLC patients. We discovered several combinations of multiple proteins that can be used for NSCLC diagnosis or assessment of response to therapies.

\section{RESULTS}

\section{Serum protein changes in lung cancer}

Eleven candidate proteins (CEA, CYFRA21.1, MIF, AGP, HGF, E-selectin, GRO, OPN, SAA, CRP, and NSE) were analyzed in serum samples from 218 NSCLC patients, 34 SCLC patients and 171 normal controls using Luminex multiplex assays. Figure 1A presents the raw data as box plots. Five of the eleven proteins (CEA, CYFRA21.1,
OPN, SAA and CRP) were significantly increased in both NSCLC and SCLC patients compared to controls. The mean level of OPN is about 4-fold higher in both NSCLC and SCLC patients than controls $\left(p<10^{-59}\right.$, and $\left.p<10^{-11}\right)$. The mean SAA level is more than 5 -fold higher in NSCLC and SCLC patients than controls $\left(p<10^{-36}\right.$ and $p<10^{-6}$ ) and the mean CRP level is increased in patients by more than 7-fold $\left(p<10^{-37}\right.$ and $\left.p<10^{-5}\right)$. The mean CEA level is 4.9-fold and 2.9-fold higher in NSCLC and SCLC, respectively $\left(p<10^{-29}\right.$ and $\left.p<0.001\right)$. The mean CYFRA21.1 level is 6.1-fold and 4.8-fold higher in NSCLC and SCLC, respectively $\left(p<10^{-18}\right.$ and $\left.p<0.001\right)$. However, MIF, AGP, HGF, sE-selectin, and GRO are not significantly different or are only marginally different in NSCLC or SCLC patients compared to controls. The only major difference between SCLC and NSCLC is NSE, which has an 8.7-fold increase in SCLC $(p=0.0011)$ but only 1.6-fold increase in NSCLC ( $p=0.000013)$ compared to controls.

To exclude the possibility that differences between patients and controls are caused by confounding variables, logistic regression was performed using protein concentration as dependent variable and sex and age as covariates. NSCLC is significantly associated with eight of the eleven proteins after adjusting for age and sex (Table 1A), suggesting that the observed associations are not due to the examined covariates. Five of the eight proteins showing significant changes in NSCLC are also significantly different in SCLC (Table 1B) after adjusting for age and sex. Furthermore, NSE is increased in SCLC patients $\left(\mathrm{OR}=2.4, \mathrm{P}_{\mathrm{adj}}=0.01\right)$ but not in NSCLC $\left(\mathrm{OR}=1.3, \mathrm{P}_{\mathrm{adj}}=0.08\right)$. The comparison of protein levels in lung cancer patients with different stages (Stage-I and II: $n=19$; Stage-III: $n=32$; Stage-IV: $n=122$ ) is presented in Supplementary Figure S1. CRP and CEA showed a small difference between early stage patients (stage I + II) and late stage patients (III + IV) but the difference is marginally significant before adjusting for multiple tests and not different after adjusting for multiple tests. Furthermore, the vast majority of the patients in this study are late stage patients and therefore stage is unlikely a major confounding factor in our studies.

We next examined whether serum protein levels are correlated with each other and the data are analyzed in three separate groups. To identify clusters of correlated proteins, the pair-wise correlation matrix is presented as a heatmap and subjected to hierarchical clustering (Figure 1B). The data indicate that only CRP and SAA are correlated in controls, while there are two subsets of correlated proteins in both lung cancer groups. The first correlated subset of proteins include CRP, SAA, AGP, GRO, HGF and OPN (average correlation coefficients are $0.17,0.56$ and 0.55 for normal controls, SCLC and NSCLC, respectively), while the second group of correlated proteins includes HGF, OPN, CYFR21.1, sEselectin, MIF and NSE (average correlation coefficients 
Table 1: Logistic regression analyses of serum proteins in NSCLC and SCLC patients

\begin{tabular}{lcccccc}
\hline NSCLC vs N & \multicolumn{3}{c}{ Unadjusted } & & \multicolumn{3}{c}{ Adjusted by Age \& Sex } \\
\hline \multicolumn{1}{c}{ Protein } & OR & $(\mathbf{9 5 \%}$ CI) & $\boldsymbol{P}$-value & OR & $(\mathbf{9 5 \%}$ CI) & $\boldsymbol{P}$-value \\
OPN & 7.00 & $(4.866-10.663)$ & $1.66 \mathrm{E}-22$ & 5.60 & $(3.734-9.018)$ & $1.43 \mathrm{E}-14$ \\
SAA & 1.81 & $(1.610-2.059)$ & $2.65 \mathrm{E}-21$ & 1.84 & $(1.574-2.201)$ & $6.64 \mathrm{E}-13$ \\
CRP & 1.73 & $(1.549-1.953)$ & $1.36 \mathrm{E}-20$ & 1.83 & $(1.567-2.173)$ & $3.74 \mathrm{E}-13$ \\
CEA & 2.18 & $(1.820-2.681)$ & $2.51 \mathrm{E}-15$ & 1.92 & $(1.544-2.443)$ & $2.47 \mathrm{E}-08$ \\
CYFRA21.1 & 1.67 & $(1.454-1.939)$ & $3.19 \mathrm{E}-12$ & 1.72 & $(1.444-2.096)$ & $1.12 \mathrm{E}-08$ \\
MIF & 0.60 & $(0.456-0.766)$ & $8.65 \mathrm{E}-05$ & 0.61 & $(0.429-0.865)$ & $6.05 \mathrm{E}-03$ \\
AGP & 1.96 & $(1.425-2.746)$ & $5.53 \mathrm{E}-05$ & 2.63 & $(1.646-4.390)$ & $1.04 \mathrm{E}-04$ \\
HGF & 1.51 & $(1.220-1.902)$ & $2.71 \mathrm{E}-04$ & 1.50 & $(1.143-1.997)$ & $4.14 \mathrm{E}-03$ \\
sE-Selectin & 0.87 & $(0.649-1.162)$ & $3.45 \mathrm{E}-01$ & 1.15 & $(0.775-1.710)$ & $4.91 \mathrm{E}-01$ \\
GRO & 1.01 & $(0.714-1.439)$ & $9.42 \mathrm{E}-01$ & 1.01 & $(0.615-1.669)$ & $9.56 \mathrm{E}-01$ \\
NSE & 1.39 & $(1.167-1.696)$ & $5.67 \mathrm{E}-04$ & 1.28 & $(0.993-1.726)$ & $8.14 \mathrm{E}-02$ \\
\hline SCLC vs N & & Unadjusted & & & Adjusted by Age \& Sex & \\
\hline \multicolumn{1}{c}{ Protein } & OR & $(\mathbf{9 5 \%}$ CI) & $\boldsymbol{P}$-value & OR & $(\mathbf{9 5 \%}$ CI) & $\boldsymbol{P}$-value \\
OPN & 11.65 & $(5.614-29.537)$ & $4.55 \mathrm{E}-09$ & 6.54 & $(2.838-19.768)$ & $1.14 \mathrm{E}-04$ \\
SAA & 1.74 & $(1.442-2.143)$ & $3.60 \mathrm{E}-08$ & 1.82 & $(1.383-2.507)$ & $6.79 \mathrm{E}-05$ \\
CRP & 1.74 & $(1.449-2.155)$ & $3.22 \mathrm{E}-08$ & 1.66 & $(1.273-2.277)$ & $5.48 \mathrm{E}-04$ \\
CEA & 1.87 & $(1.434-2.555)$ & $1.76 \mathrm{E}-05$ & 1.64 & $(1.104-2.613)$ & $2.06 \mathrm{E}-02$ \\
CYFRA21.1 & 1.71 & $(1.332-2.265)$ & $8.12 \mathrm{E}-05$ & 1.79 & $(1.232-2.795)$ & $4.90 \mathrm{E}-03$ \\
MIF & 0.68 & $(0.416-1.064)$ & $1.08 \mathrm{E}-01$ & 0.63 & $(0.338-1.173)$ & $1.47 \mathrm{E}-01$ \\
AGP & 1.65 & $(0.882-3.187)$ & $1.26 \mathrm{E}-01$ & 1.18 & $(0.470-3.048)$ & $7.32 \mathrm{E}-01$ \\
HGF & 1.09 & $(0.779-1.468)$ & $6.03 \mathrm{E}-01$ & 1.01 & $(0.663-1.564)$ & $9.50 \mathrm{E}-01$ \\
SE-Selectin & 0.87 & $(0.492-1.493)$ & $6.15 \mathrm{E}-01$ & 1.01 & $(0.474-2.179)$ & $9.75 \mathrm{E}-01$ \\
GRO & 0.64 & $(0.346-1.171)$ & $1.48 \mathrm{E}-01$ & 0.37 & $(0.126-1.004)$ & $5.53 \mathrm{E}-02$ \\
NSE & 2.47 & $(1.707-3.840)$ & $1.19 \mathrm{E}-05$ & 2.42 & $(1.411-5.309)$ & $1.33 \mathrm{E}-02$ \\
\hline & & & & &
\end{tabular}

are $0.14,0.49$ and 0.34 for normal controls, SCLC and NSCLC, respectively). Interestingly, CEA is not correlated with any other protein (average correlation coefficients $0.09,0.08$ and 0.003 for the three subject groups).

\section{Correlations with patient characteristics}

Metastatic patients have significantly higher CEA than non-metastatic patients $(\mathrm{FC}=2.1, p<0.004)$ (Supplementary Figure S2). MIF is marginally lower in patients with metastasis than without metastasis $(\mathrm{FC}=0.8$, $p=0.1$ ). No other significant differences were found.

\section{Diagnostic value for NSCLC}

Area-under-the-curve (AUC) in receiver-operatingcharacteristic (ROC) curves were examined for each of the eleven proteins for their ability to separate NSCLC patients from controls. As shown in Figure 2A, some proteins have excellent but not perfect AUC values. The best proteins are OPN $(\mathrm{AUC}=0.919), \mathrm{CRP}(\mathrm{AUC}=0.832)$, SAA $(A U C=0.823)$ and $C E A(A U C=0.805)$. The cancer antigens CYFRA21.1 and NSE have AUC values of 0.77 and 0.60 , respectively.

Subsequently, we examined AUC values using all combinations of three or four proteins consisting of OPN, CEA, CRP, SAA, CYFRA21.1 and NSE. As shown in Figure 2B, AUC for NSCLC can be improved by multiple combinations. Four best models with three proteins have near perfect AUC values ( 0.96) and all four models contain both OPN and CEA, with a third protein being one of the other four proteins (NSE, CYFRA21.1, CRP, or SAA) (Figure 2B). However, no model with four proteins further improved the diagnostic value compared to the best three-protein models (Figure 2B).

Table 2 presents the sensitivity values for individual proteins as well as different models at four different specificity thresholds ( $90 \%, 95 \%, 99 \%$ and $100 \%)$. Among 
individual proteins, the best performing protein is OPN, which has a sensitivity of $78 \%, 72 \%, 58 \%$ and $29 \%$ at specificity of $90 \%, 95 \%, 99 \%$ and $100 \%$, respectively. The performance for CEA, CRP and SAA are comparable but worse than OPN. At the highest specificity requirement (99\% and 100\%), four multivariate models with three proteins (OPN-CEA plus CYFRA21.1, NSE, CRP or SAA) have reached sensitivity levels of approximately $70 \%$ and $60 \%$ (Table 2), suggesting that these protein combinations possess excellent diagnostic potential.

The ability of each protein to distinguish NSCLC patients from SCLC patients was also examined. As shown in Supplementary Figure S3, the best AUC value for individual proteins is 0.722 (NSE). Protein combinations could not improve the performance over single proteins. We did not evaluate the diagnostic potential for these proteins for SCLC due to the small sample size.

\section{Changes in response to therapy}

Serum samples before and post treatment were available from 68 NSCLC patients, all of whom received platinum-based therapies. The treatment can be grouped in three major categories based on the other treatment drugs.
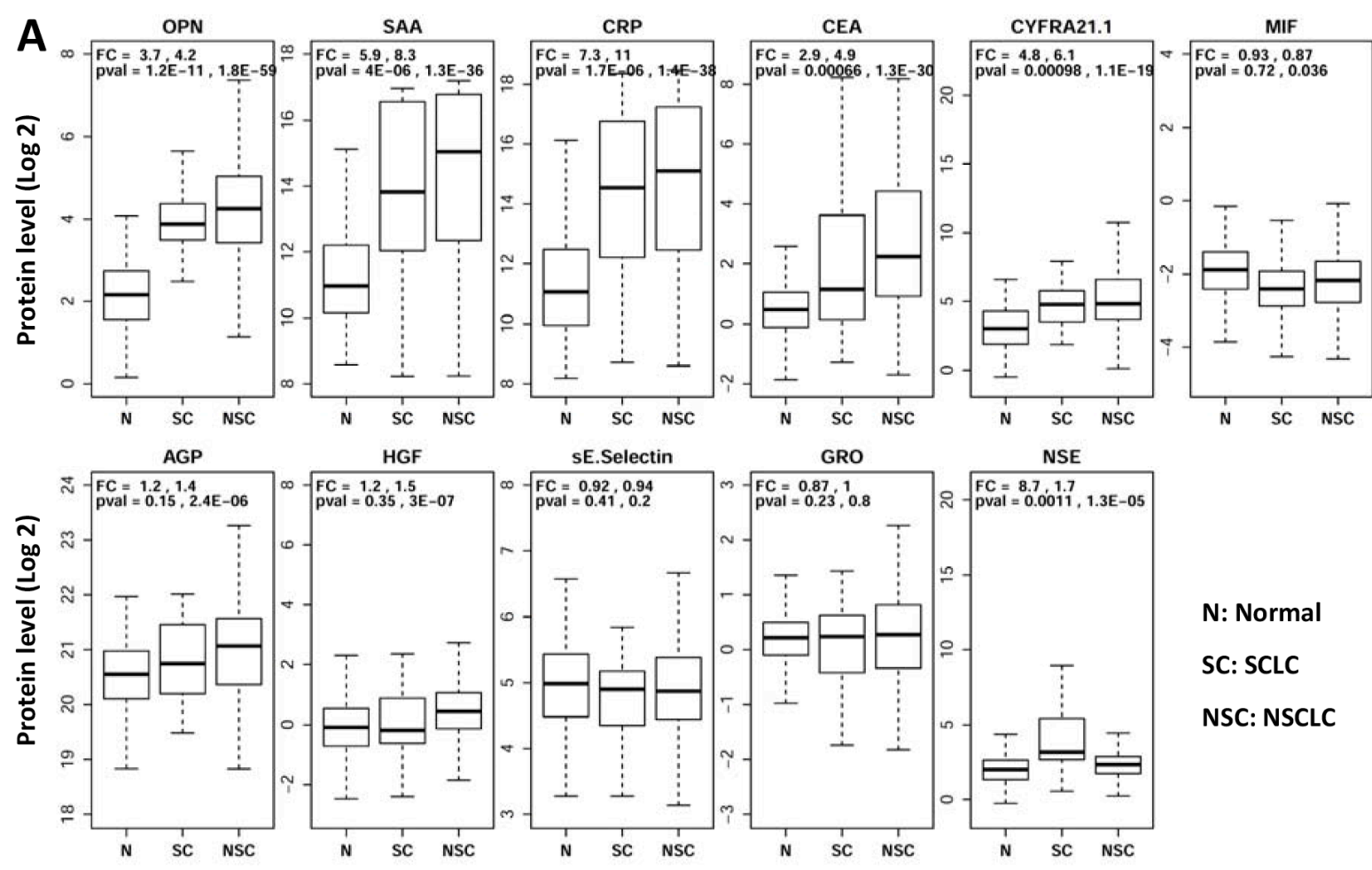

N: Normal

SC: SCLC

NSC: NSCLC

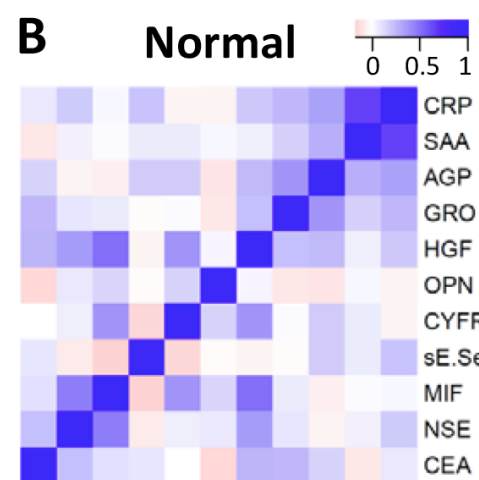

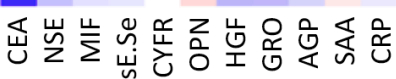

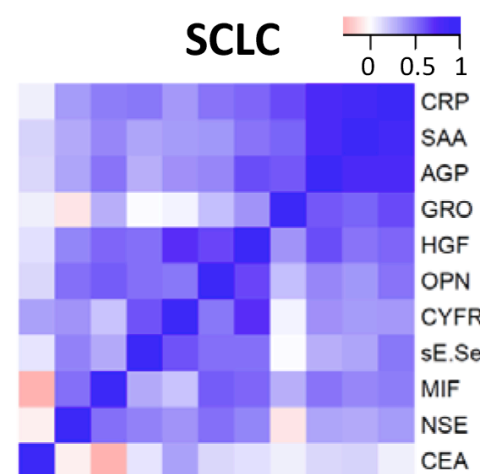

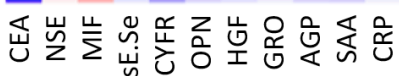

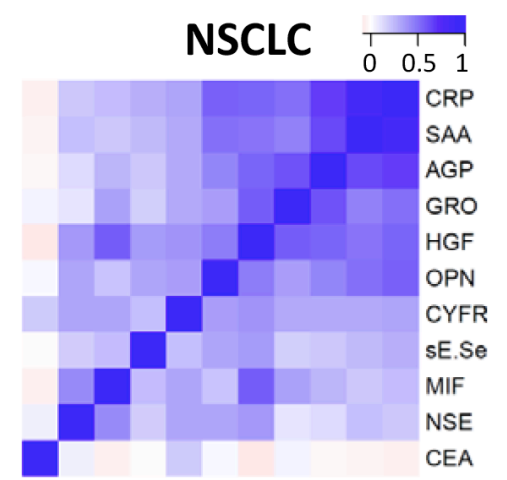

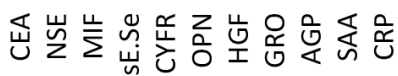

Figure 1: Distribution of serum protein levels measured in pre-treatment samples from $171 \mathrm{normal}(\mathrm{N}), 34 \mathrm{small}$ cell (SC) and 218 non-small cell (NSC) lung cancer patients. (A) Each plot represents distribution of protein levels on log 2 scale in three different groups. Fold change (FC) and $p$-values (pval) are shown on top of these plots (first value: SCLC vs Normal Controls; second value: NSCLC vs Normal Controls). (B) Heatmaps representing pair-wise correlations between levels of 11 proteins in three separate groups of subjects. Protein orders are based on clustering results and dendrograms are not shown here. 
Table 2: Sensitivity of individual and combinations of proteins at different specificity threshold for NSCLC

\begin{tabular}{lcccccc}
\hline \multirow{2}{*}{ Protein } & AUC & \multicolumn{3}{c}{ Sensitivity at specificity of } & p-val \\
\cline { 3 - 7 } & & $\mathbf{9 0 \%}$ & $\mathbf{9 5 \%}$ & $\mathbf{9 9 \%}$ & $\mathbf{1 0 0 \%}$ & \\
\hline OPN & $0.92(0.91-0.93)$ & 77.5 & 72.5 & 57.8 & 28.9 & $1.1 \mathrm{E}-45$ \\
CEA & $0.80(0.78-0.83)$ & 56.4 & 50.5 & 41.3 & 35.8 & $5.2 \mathrm{E}-25$ \\
CRP & $0.83(0.81-0.85)$ & 63.8 & 52.8 & 39.9 & 39.5 & $2.5 \mathrm{E}-29$ \\
SAA & $0.82(0.80-0.84)$ & 63.8 & 56.0 & 30.7 & 21.1 & $7.5 \mathrm{E}-28$ \\
CYFRA21.1 & $0.77(0.75-0.79)$ & 42.4 & 35.9 & 25.8 & 24.9 & $6.5 \mathrm{E}-20$ \\
NSE & $0.60(0.57-0.63)$ & 19.7 & 12.8 & 11.0 & 9.6 & $5.5 \mathrm{E}-04$ \\
AGP & $0.67(0.64-0.70)$ & 36.5 & 30.5 & 14.0 & 13.0 & $5.8 \mathrm{E}-06$ \\
HGF & $0.66(0.63-0.68)$ & 18.8 & 11.9 & 4.6 & 0.5 & $7.3 \mathrm{E}-08$ \\
MIF & $0.60(0.57-0.63)$ & 17.0 & 4.10 & 1.8 & 0.0 & $8.1 \mathrm{E}-04$ \\
SE-Selectin & $0.54(0.51-0.57)$ & 10.5 & 6.4 & 0.6 & 0.0 & $1.8 \mathrm{E}-01$ \\
GRO & $0.51(0.47-0.55)$ & 20.5 & 17.5 & 7.5 & 2.0 & $7.9 \mathrm{E}-01$ \\
CEA OPN CRP & $0.96(0.95-0.96)$ & 91.7 & 87.6 & 74.6 & 62.4 & $<\mathrm{E}-300$ \\
CEA OPN NSE & $0.96(0.95-0.96)$ & 90.3 & 81.0 & 70.1 & 63.0 & $<\mathrm{E}-300$ \\
CEA OPN CYF & $0.96(0.95-0.96)$ & 90.8 & 84.7 & 69.4 & 65.0 & $<\mathrm{E}-300$ \\
CEA OPN SAA & $0.96(0.95-0.96)$ & 90.3 & 85.3 & 62.7 & 60.2 & $<\mathrm{E}-300$ \\
CEA OPN CRP SAA & $0.96(0.96-0.96)$ & 91.7 & 88.1 & 67.0 & 61.0 & $<$ E-300 \\
CEA OPN CRP CYF & $0.96(0.96-0.96)$ & 92.0 & 88.4 & 68.4 & 64.0 & $<\mathrm{E}-300$ \\
CEA OPN SAA CYF & $0.96(0.95-0.96)$ & 91.0 & 87.3 & 69.9 & 61.5 & $<$ E-300 \\
CEA OPN CRP NSE & $0.95(0.95-0.96)$ & 91.1 & 88.6 & 69.0 & 66.7 & $<$ E-300 \\
CEA OPN SAA NSE & $0.95(0.95-0.96)$ & 90.7 & 87.5 & 69.3 & 62.6 & $<$ E-300 \\
CEA OPN CYF NSE & $0.95(0.95-0.96)$ & 89.0 & 77.9 & 69.4 & 65.1 & $<$ E-300 \\
\hline CYF: CYFRA21. & & & & & &
\end{tabular}

CYF: CYFRA21.1.

The first group included 43 patients treated with platinum and pemetrexed (PEM) and the second group had 17 patients treated with platinum and taxane (TAX), while the third group includes 8 patients that received platinum plus gemcitabine (GEM). For each individual patient, the ratios between protein levels post-treatment over pre-treatment were calculated for each protein. The mean ratios in each of the three treatment groups are presented in Figure 3. The data indicate that several proteins were reduced post treatment in all three treatment groups. Proteins with greater reductions after treatment include CYFRA21.1, NSE, CRP and SAA. CEA is very interesting because its mean level is reduced post treatment in the gemcitabine and taxane treatment groups but was actually increased in the pemetrexed treatment group.

Figure 4 shows the changes of individual patients in each of the three treatment groups. The first interesting observation is the great variability among different patients. For example, in the PEM group, CEA is greatly increased after treatment in some patients while some other patients have reduced levels. A subset of patients also showed dramatic reduction in the levels of CYFRA21.1,
NSE, CRP and SAA. Furthermore, these four proteins are consistently changed or unchanged in most patients. Finally, there are higher percentages of patients with severe reduction in the GEM treatment compared to Taxane and PEM treatment.

To assess the overall changes of serum protein profile, we computed a therapy response index (TRI). The ratio of post/pre-treatment concentration was calculated for each patient and each protein. TRI for each patient is the sum of the $\log 2$ ratios for the proteins used for TRI calculation. TRI can be calculated using any number of proteins but we focused on four proteins (CYFRA21.1CRP-SAA-NSE) and five proteins (4 proteins + CEA). TRI can also be computed for different time points post treatment. TRI is shown as dot plots for selected combinations of proteins and time points (Figure 5) and similar data were obtained for other time points and other protein combinations. We also examined the percentage of patients with different levels of TRI. Based on the distribution of TRI in the entire cohort, we selected two thresholds to examine the treatment outcomes. A TRI $<2^{-10}$ (or 1/1028) is considered as good response, while a 
TRI of $2^{-5}-2^{-10}$ is considered moderate response. At the 3 month post-treatment time point, $27 \%$ of the patients had a TRI $<2^{-10}$ and $17.5 \%$ of the patients had a TRI of $2^{-5}-2^{-10}$, while $55.5 \%$ of the patients had only modest reduction, unchanged or moderate increase (TRI $>2^{-5}$ ) (Figure 5). Since these serum proteins are increased in NSCLC patients compared to controls, their reduction in response to therapy should indicate reduction of tumor burden after therapy and the degree of reduction may be a reflection of the success of therapy.

We next examined the potential difference in treatment outcome between the three treatment groups (Figure 5). Using TRI of $2^{-10}$ as indication of good response to therapy, $62.5 \%$ of the patients receiving gemcitabine achieved good response compared to $26 \%$ and $13 \%$ for the pemetrexed groups at 3 and 5 months post therapy $(\mathrm{OR}=5.1, p=0.04 ;$ and $\mathrm{OR}=10.8, p=0.01$, respectively $)$. In the taxane group, $12 \%$ and $18 \%$ of the patients achieved good response at 3 and 5 months, which are significantly different from the gemcitabine treatment group $(\mathrm{OR}=10.8$, $p=0.01$ and $\mathrm{OR}=7.0, p=0.06$ ), respectively) but not significantly different from the pemetrexed group. These results may suggest that platinum plus gemcitabine is a better treatment for NSCLC.

\section{Prediction of therapy response using proteins measured before therapy}

We also examined whether protein changes in response to therapy can be predicted by the protein levels before treatment. Figure 6A plots the correlation between TRI and the pre-treatment levels for individual proteins. These results suggest that patients with good response tend to have much higher protein levels for CRP, SAA and CYFRA21.1. Although patients with the highest protein levels tend to respond better, not all patients with high expression respond well to treatment.

Subsequently, we examined whether the response to treatment and the total levels of multiple proteins. Surprisingly, very high correlations were observed
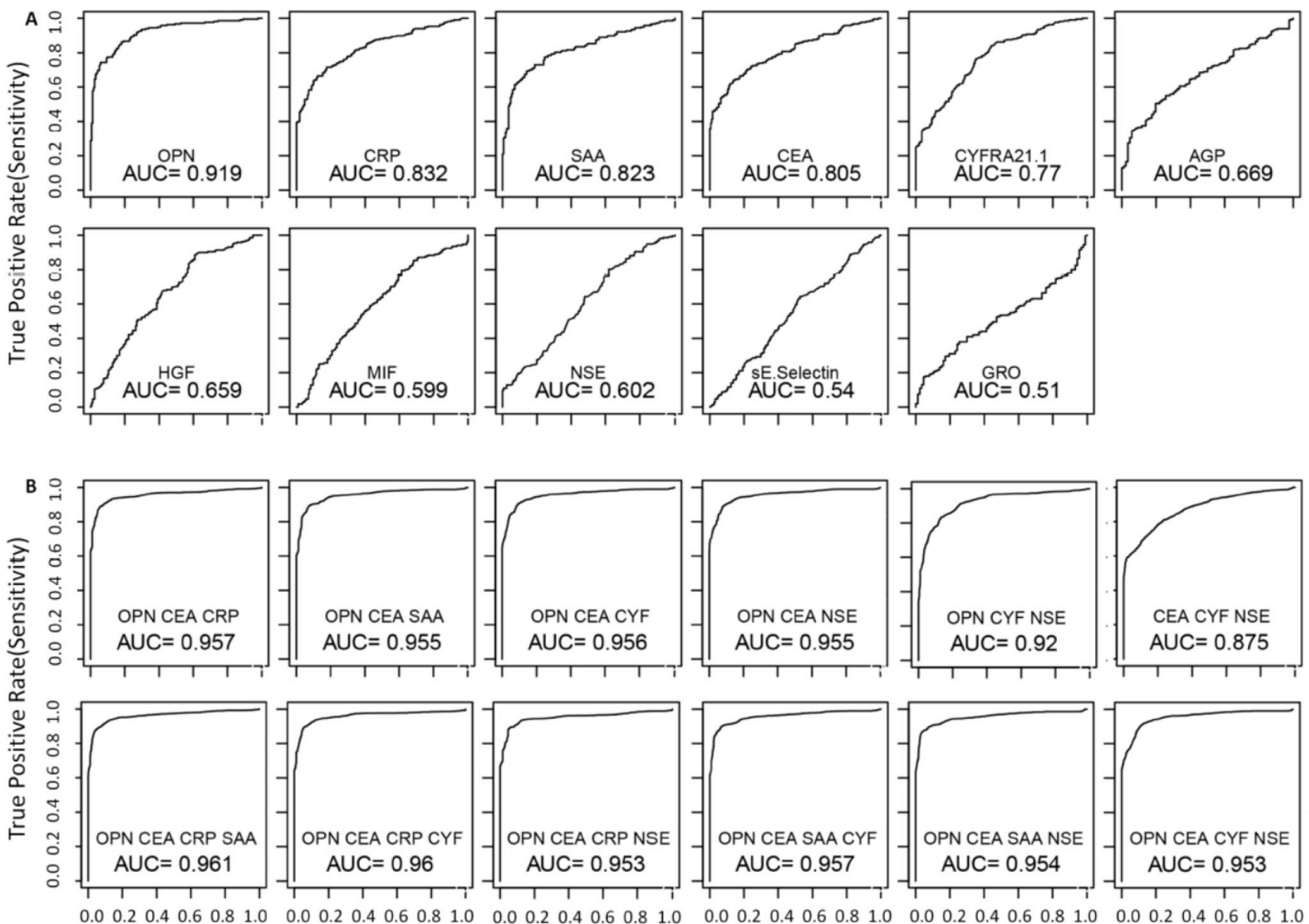

False Posoitive Rate(1-Specificity)

Figure 2: Receiving-operator-characteristics (ROC) curves that evaluate the ability to distinguish NSCLC patients from healthy controls. Single proteins $(\mathbf{A})$ and multi-protein models $(\mathbf{B})$ were used for the analyses. For multi-protein models, linear discriminate analysis was performed using all possible combinations for 3 or 4 of the 6 top performing proteins (OPN, CEA, CRP, SAA, CYFRA 21-1 and NSE). The performance of each model was evaluated using leave one out cross validation method. The utility of serum proteins as NSCLC biomarkers was evaluated using the area-under-curve (AUC) of the ROC curves for different models. ROC curves are only shown for the top performing models. 
between TRI and the total protein levels of multiple proteins. Representative data for four proteins (CRPSAA-CYFRA21.1-NSE) are shown in Figure 6B. The data suggest again that patients with higher protein levels have better TRI.

\section{DISCUSSION}

LC is a cancer with high mortality and morbidity in China and many other countries in the world and LC patients can be treated with surgery, chemotherapy and radiotherapy [45]. A number of studies have searched for serum protein biomarkers that can distinguish LC from controls and various associations have been suggested in the literature [46]. However, no biomarker reported so far is of great clinical interest due to the poor specificity and sensitivity. Therefore, the search for better biomarkers, either individual molecules or specific combinations of molecules, continues.
In this study, we analyzed 11 serum proteins in a relatively large cohort of LC patients and healthy controls and identified six proteins (OPN, CEA, NSE, CYFRA21.1, CRP, and SAA) that, in combination, may be of great clinical interest for NSCLC. The first potential application of these six proteins is related to NSCLC diagnosis. Among individual proteins, OPN is the best biomarker for diagnosing NSCLC $(\mathrm{AUC}=0.919)$ in this study. This AUC value is also better than any individual proteins reported for NSCLC in the literature. OPN has been reported to be elevated in NSCLC serum and tissues and is associated with poor survival $[25,26]$. In this study, NSCLC patients have 4.2 times higher OPN and SCLC patients have 3.7 times higher OPN than controls $\left(p<10^{-58}\right)$. The AUC value for NSCLC is 0.919 , indicating a good diagnostic potential.

The next two best performing individual proteins for NSCLC are CRP (AUC $=0.832)$ and SAA $(A U C=0.823)$, two inflammatory proteins. It has been reported that CRP
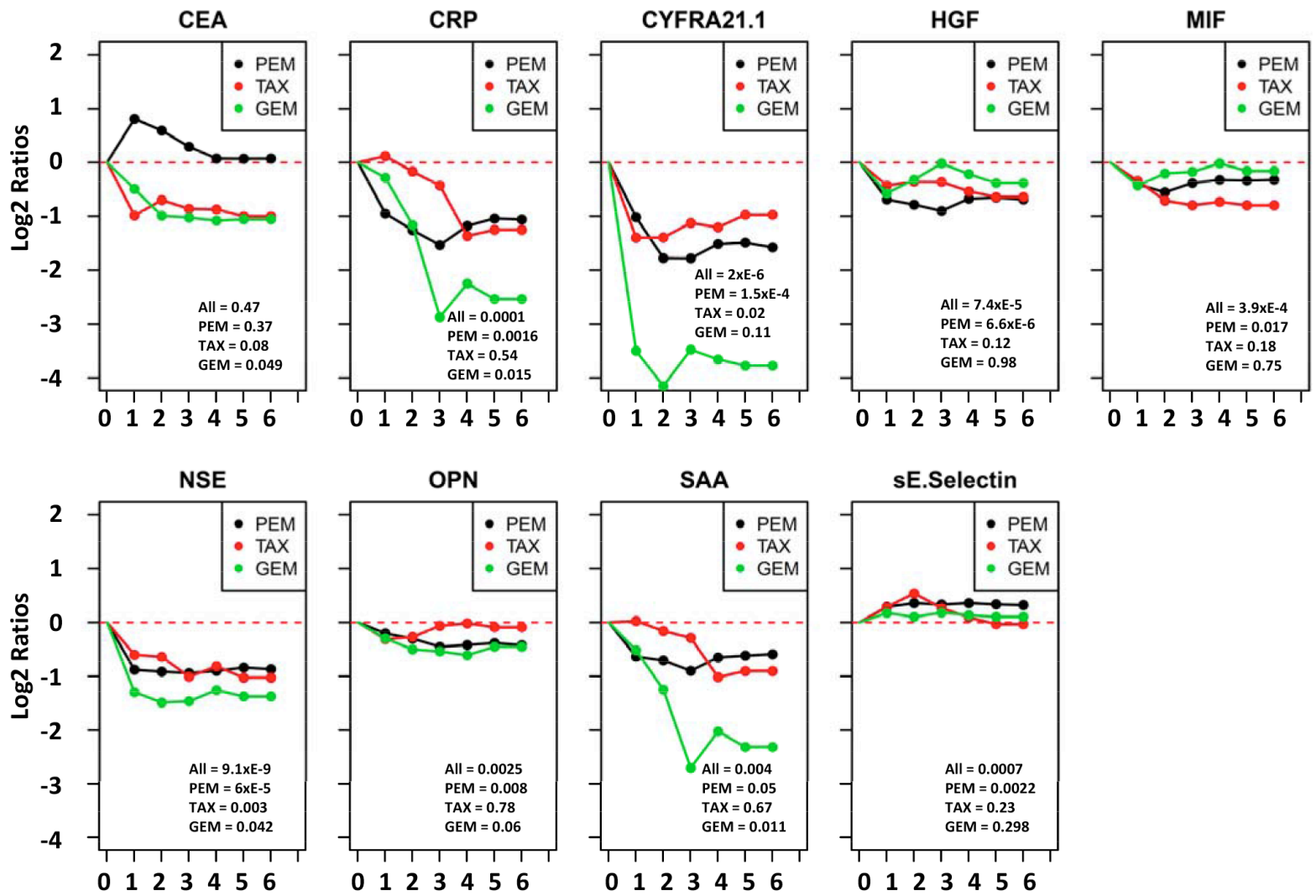

Time points post therapy (Months)

Figure 3: Trend lines of mean protein levels post therapy in three different treatment groups of NSCLC patients. Subjects are divided into three treatment groups, which received platinum plus one of the three drugs: $P E M=$ pemetrexed, TAX $=$ taxane, $\mathrm{GEM}=$ gemcitabine. The time point before treatment is set as 0 time point and the mean protein levels before treatment in each group are set as zero for the group. For each of the six months after treatment, the protein levels of each patient is divided by the pretreatment level in that patient to calculate the post $v s$ pre-therapy ratio, which is then $\log 2$ transformed. The $\log 2$ ratios of all patients in the treatment group are averaged and plotted. If data are missing for any time point for a patient, measurement at the previous time point is used for data analysis. Paired T test was used to compare each post treatment time point and the pretreatment time point for statistical significance. Values at lower-right corner of each chart are $p$-values for pre-therapy $v s 3$-months post therapy comparisons for three treatment groups. $P$ values for the 4, 5 and 6 month time points are similar but not shown. 
is higher in NSCLC patients compared to healthy controls but has modest prognostic value for survival in NSCLC patients $[19,20]$. SAA was found to be increased by 14 -fold in NSCLC patients compared to controls [47] and higher
SAA level was also associated with poor survival in NSCLC [48]. This study with 218 NSCLC patients and 171 healthy controls convincingly shows significantly elevated CRP and SAA in LC patients compared to
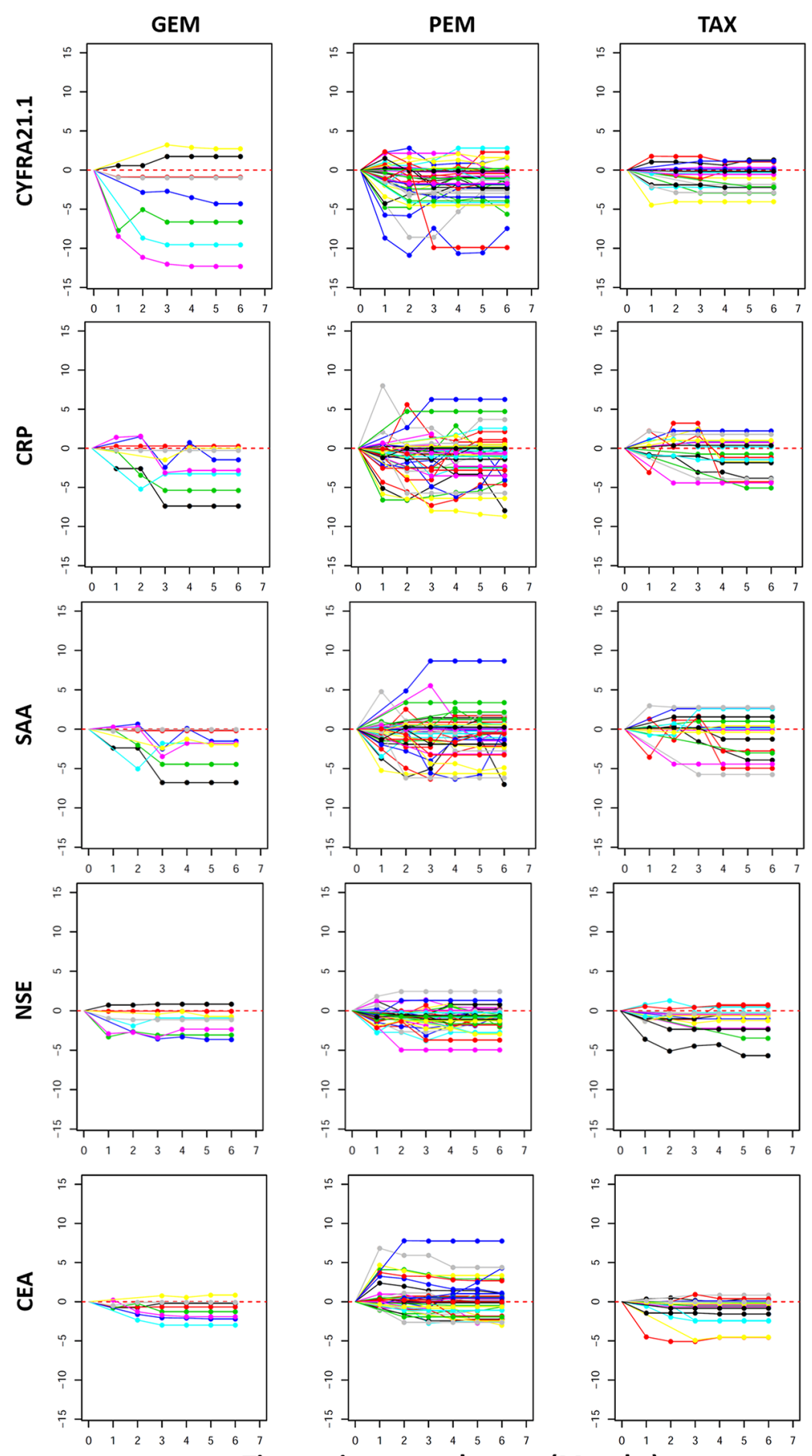

Time points post therapy (Months)

Figure 4: Line plots depicting post therapy changes in the protein levels in individual NSCLC patients. Plotted on the Y axis are Log 2 ratios of post vs after treatment protein levels as explained in Figure 3 and X-axis plots the treatment time points. Plotted data are for individual patients (each represented by a line) to illustrate the variable response to treatment. Within each treatment group (GEM, PEM or TAX), each patient is represented by lines with the same color in plots for different proteins. If data is missing for any time point, measurement at the previous time point is used for data analysis. 
healthy controls. CRP is 11.0 times higher in NSCLC and 7.3 times higher in SCLC patients compared to controls. SAA is 8.3 times higher in NSCLC and 5.9 times higher in SCLC patients compared to controls. The inflammatory response to tumor and expression of CRP and SAA in tumor cells [49] may account for the coordinated elevation of SAA and CRP in cancer patients.

Three widely reported tumor antigens (CEA, NSE and CYFRA21.1) may be of diagnostic value for NSCLC although individually their AUC is modest (0.805, 0.77 and 0.60 , respectively). CEA is 4.9 times higher in NSCLC and 2.9 times higher in SCLC. CYFRA21.1 is 6.1 times higher in NSCLC and 4.8 times higher in SCLC. NSE is only 1.7 times higher in NSCLC but 8.7 times higher in SCLC. NSE is indeed the only protein that is significantly higher in SCLC than NSCLC and may be an excellent biomarker for SCLC. The AUC values observed in this study for these three cancer antigens are in lines with findings reported in other studies [50].

\section{A}

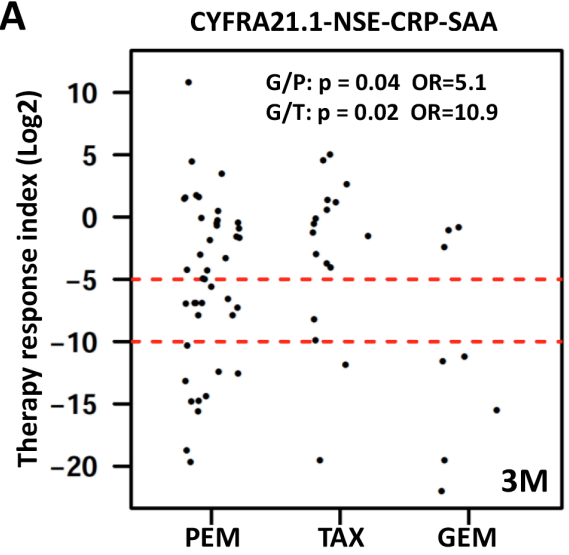

C

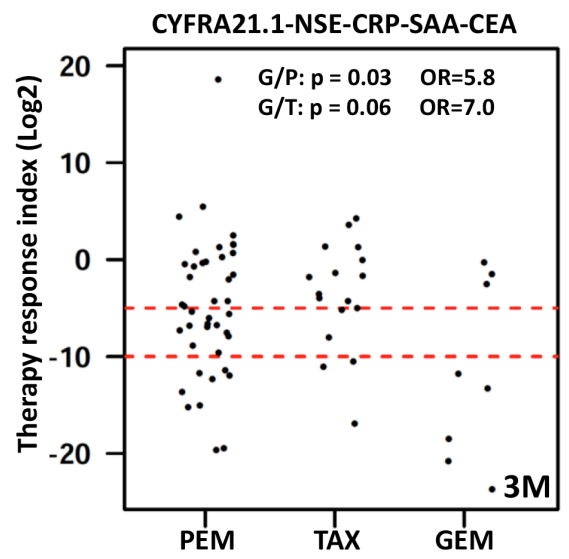

One of the most important discoveries in this study is that combinations (models) with multiple proteins can significantly improve the performance of serum proteins for diagnosis of NSCLC. Only six proteins with better performance based on individual proteins (OPN, CEA, CRP, SAA, CYFRA 21-1 and NSE) were used in the combination analyses. We evaluated all 30 combinations with three proteins in each model and all 15 models with four proteins in each model. Four models, each with three proteins, reached an outstanding AUC near 0.96. This is the best AUC achieved for LC to our knowledge. Interestingly, all four models contain OPN and CEA, with a third protein being CYFRA21.1, NSE, CRP or SAA. Although four models have similar performance, we believe that the models with tumor antigens (OPN-CEA-CYFRA21.1 and OPN-CEA-NSE) may be more appropriate than the models with inflammatory proteins (OPN-CEA-CRP and OPN-CEA-SAA) because CRP and SAA are elevated in many diseases including other cancers. Therefore,
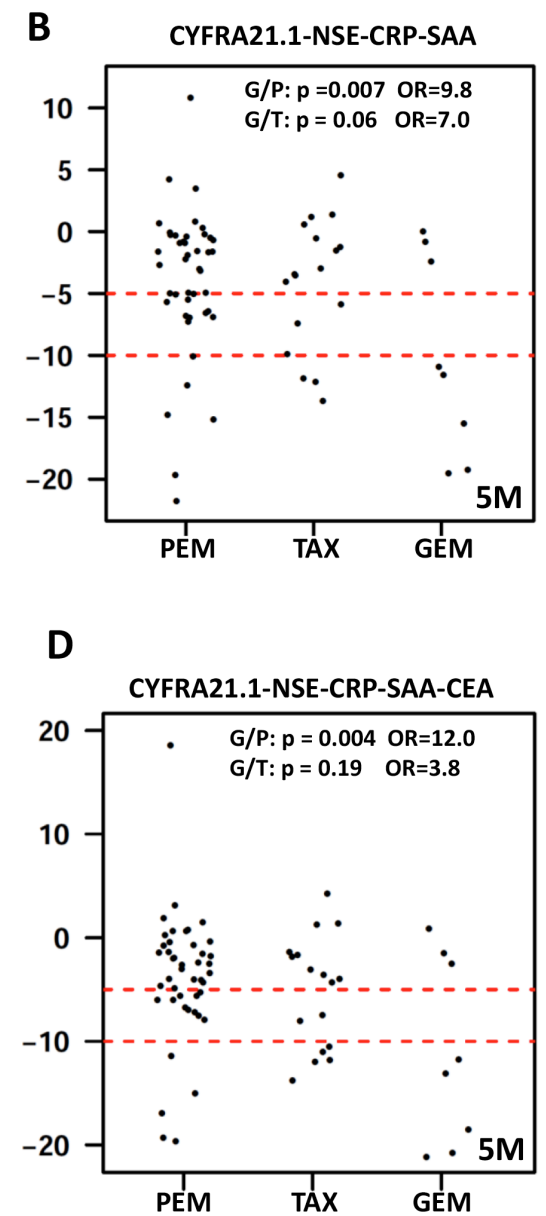

Figure 5: Dot plots of therapy response index (TRI) calculated for each patient. TRI was calculated for each patient (represented by a dot) and time point as explained in the text. Presented here are representative dot plots for TRI calculated using four proteins (upper panel) or five proteins (lower panel) at the 3 month time point (left panels marked as $3 \mathrm{M}$ ) and the 5 month time point (right panels marked as $5 \mathrm{M}$ ). Data for other time points are similar and not shown here. Dashed red lines represent the cutoff values for good response $\left(\mathrm{TRI}<2^{-10}\right)$ and moderate response $\left(\mathrm{TRI}<2^{-5}\right)$. Differences in treatment response were compared between GEM and PEM treatment groups $(\mathrm{G} / \mathrm{P})$ and between GEM and TAX groups $(\mathrm{G} / \mathrm{T})$ by calculating the odds ratio $(\mathrm{OR})$ and associated $p$ value using TRI $<2^{-10}$ as cutoff for good response. 
the combinations of four serum proteins (OPN, CEA, CYFRA21.1 and NSE) may be excellent biomarkers for NSCLC diagnosis. Their potential for NSCLC screening should also be evaluated in future studies.

The second most important finding in this study is related to biomarkers that can assess the response to therapies and indication of disease recurrence. Previous studies have shown that poor outcome is predicted by high levels, slower and incomplete decline in CEA, CYFRA 21-1 and nucleosomal DNA [42-44]. Although these biomarkers are of some help to the management of individual patients, these tools are not ideal because the differences between the responder groups and non- responder groups are usually small and overlap between the groups is quite significant. In this study, we examined the reduction of serum proteins by calculating the ratios between post- and pre-therapy concentrations and identified five proteins (CYFRA21.1, CEA, NSE, CRP and SAA) that are severely reduced in subsets of NSCLC patients in response to therapy. In many cases, multiple proteins are coordinately reduced by therapy. Therefore, we computed for each patient a therapy response index (TRI). TRI clearly identified a subset, approximately a quarter, of the NSCLC patients that have dramatically reduced protein levels (TRI $<2^{-10}$ ). These patients responded very well to therapy as measured by the
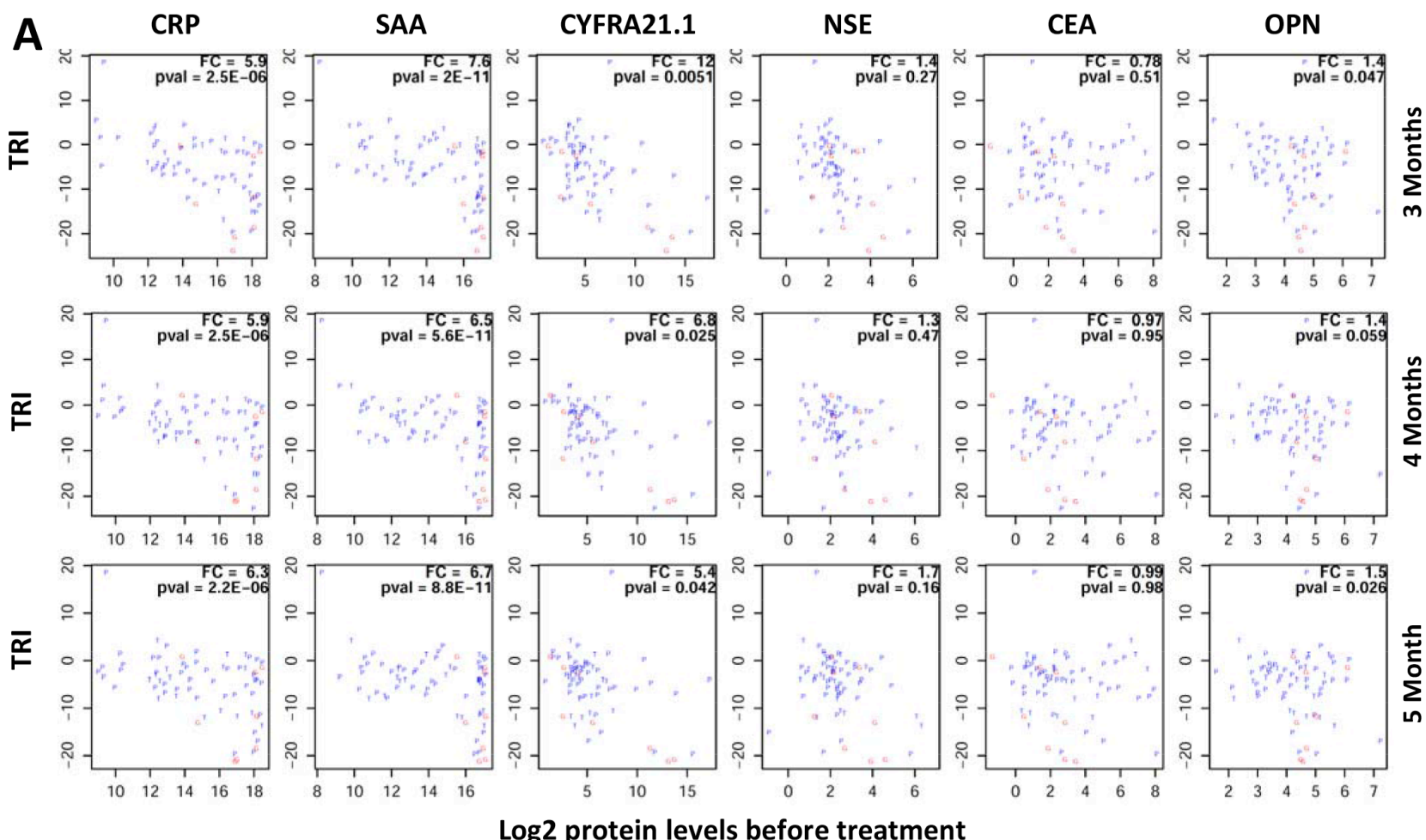

Log2 protein levels before treatment
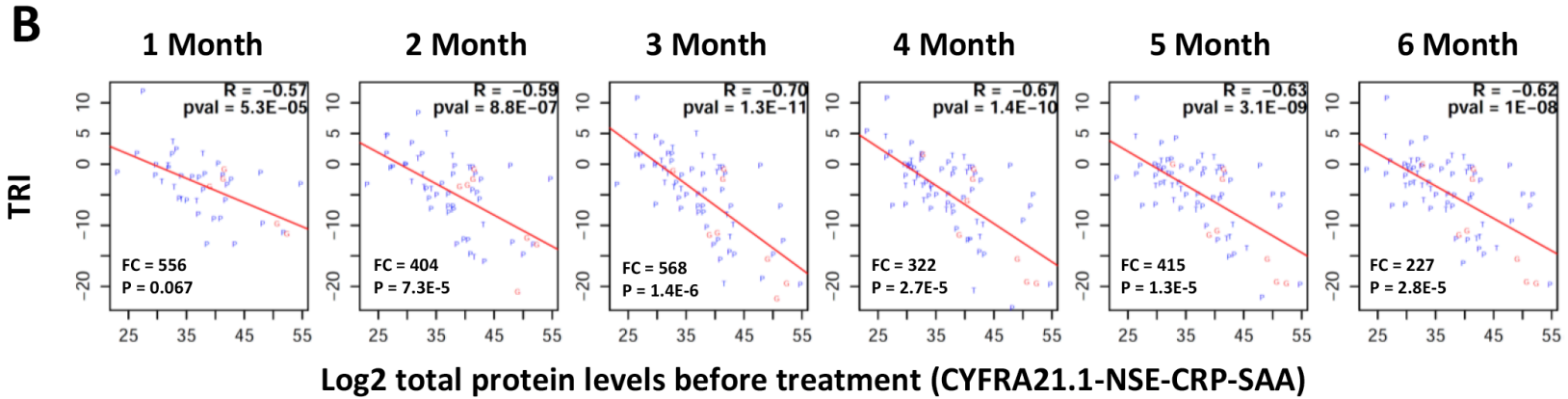

Figure 6: Correlation between pre-treatment protein levels and therapy response index (TRI). TRI was calculated using a combination of four proteins (FRA21.1-CRP-SAA-NSE). Each patient is represented by a letter (P, G or T) corresponding to their treatment groups (PEM, GEM or TAX). (A) Plots showing correlations between TRI (y-axis) and pre-therapy protein levels for individual proteins (x-axis). FC (fold change) is the ratio of mean protein levels for patients with TRI $<2^{-10}$ (good response) over mean protein level for patients with TRI $\geq 2^{-10}$. (B) Plots showing correlations between TRI (y-axis) and the sum of protein levels for four proteins (CYFRA21.1, NSE, $\mathrm{CRP}$ and SAA) at the pre-therapy time point (x-axis). FC (fold change) is the ratio of mean total protein levels for patients with TRI $<2^{-10}$ (good response) over mean total protein level for patients with $\mathrm{TRI} \geq 2^{-10}$. R: correlation coefficient; pval $=p$ value. Treatment time points are shown on top of the correlations plots. 
examined serum proteins that are known to be implicated in NSCLC. Unfortunately, survival data are not available for these patients to correlate TRI and patient survival.

Since prognostic biomarkers for patient response to therapy can improve patient care, we examined whether serum protein levels can predict therapeutic response in NSCLC. It was interesting to find out that almost all patients with great TRI have high levels of CYFRA21.1, CRP and SAA as well as slightly higher levels of NSE and OPN. Although the response to treatment is clearly associated with individual protein levels, the total protein levels of multiple proteins showed very good correlation with TRI. However, the clinical implication of these findings requires further investigation. It is now unclear whether the reduction of these proteins translates into long term survival benefit. Since these proteins are clearly NSCLC biomarkers, we believe that their reduction by therapy should be correlated with patient outcome. It is also unknown why TRI is correlated with pretreatment protein levels. One likely possibility is that the therapeutic response can be measured more effectively with biomarkers that are more highly expressed in the patients. This is a logic hypothesis and suggests that different biomarkers will be needed to monitor therapeutic outcome for different subsets of patients, the essence of personalized or precision medicine.

\section{MATERIALS AND METHODS}

\section{Human subjects and serum samples}

The selection criteria for patients with lung cancer were as follows: 1) pathologically confirmed patients (the diagnoses in all patients were confirmed each time by microscopic examination of the material obtained during bronchoscopy, biopsy, or surgery); 2) patients had no history of other carcinomas. A total of 218 NSCLC patients, 34 SCLC patients in Jiangsu Cancer Hospital between October 2011 and December 2012 and 171 healthy control subjects from Nanjing were used in the present study. Blood samples were collected from patients at the time of diagnosis and before any treatment (surgery and/or chemotherapy). Furthermore, blood samples from patients treated with surgery and/or chemotherapy were also collected monthly. Samples were centrifuged for $10 \mathrm{~min}$ at $3,000 \mathrm{rpm}$ at $4^{\circ} \mathrm{C}$, and serum was subsequently frozen at $-80^{\circ} \mathrm{C}$ until use. This study has been approved by the human subject ethics committee of the Jiangsu Cancer Hospital and informed consent signed by the study subjects.

\section{Luminex assays}

Luminex assays for all proteins were obtained from Millipore (Millipore Inc., Billerica, MA, USA). The assays were performed according to the manufacturer's instructions. Briefly, serum samples were incubated with antibody-coated microspheres, followed by biotinylated detection antibody. Proteins were detected by incubation with phycoerythrin-labeled streptavidin and the resultant bead immuno-complexes were read on a FLEXMAP3D (Luminex, TX, USA) with the following instrument settings: events/bead: 50, minimum events: 0, Flow rate: $60 \mathrm{ul} / \mathrm{min}$, Sample size: $50 \mathrm{ul}$, discriminator gate: 8000-13500. Median fluorescence intensity (MFI) was collected and used for calculating protein concentration.

\section{Statistical analysis}

Protein concentrations were estimated using a regression fit to the standard curve with known concentration included on each plate using a serial dilution series. The concentrations were logarithmically transformed prior to all statistical analyses to achieve normal distribution. The comparisons for 3 groups $(\mathrm{N}$, SCLC, and NSCLC) were made by ANOVA followed by pair-wise group comparisons using $t$-tests (Figure 1A). To examine the relationships between disease status and serum protein levels, logistic regression was used by including age and sex as co-variates (Table 1). To examine the correlation between levels of 11 proteins, the pairwise correlations were computed using Pearson correlation in controls, SCLC and NSCLC groups separately. Clustering and visualization of correlation matrix was performed using hierarchical clustering method and heatmap (Figure 1B). The diagnostic power of individual proteins and their combinations to differentiate controls and NSCLC patients was assessed using the area under the curve (AUC) of the receiver operating characteristic (ROC) curves (Figure 2). Sensitivity values of individual and combinations of proteins at different specificity thresholds $(90 \% ; 95 \% ; 99 \% ; 100 \%)$ were computed (Table 2). This ROC analysis was not performed for SCLC patients due to smaller sample size. $\log _{2}$ ratios of protein levels post- $v s$ pre-treatment were computed at six different time points (1-6 month post-treatment). If data are missing for any time point, measurement at the previous time point was used for data analysis. For pre-post comparisons a paired $t$-test was used to compute $p$-values for individual treatment groups and all patients combined (Figure 3). The trend of pre- and post-treatment protein levels in individual patients was visualized using line plots (Figure 4). Therapy Response Index distribution was plotted for each patient at two time points (3-months and 5-months post treatment). The comparison of TRI values in three treatment groups (PEM, TAX, and GEM) was made using fisher's exact test (Figure 5). To examine the relation between the therapy response and protein levels before treatment, we computed Pearson correlation coefficient between TRI values and individual protein levels of CRP, SAA, CYFRA21.1, NSE, CEA and OPN. Correlation of TRI values with total protein levels before treatment was also computed (Figure 6). All statistical 
analyses were performed using the $\mathrm{R}$ language and environment for statistical computing ( $\mathrm{R}$ version 2.15.1; $\mathrm{R}$ Foundation for Statistical Computing; www.r-project.org).

\section{ACKNOWLEDGMENTS AND FUNDING}

This research is supported by the National Science Foundation of China (grant number 81272244 and 81372396) and general program from Jiangsu province health department (grant number H201410).

\section{CONFLICTS OF INTEREST}

None.

\section{REFERENCES}

1. Mulshine JL, Sullivan DC. Clinical practice. Lung cancer screening. N Engl J Med. 2005; 352:2714-2720.

2. Parkin DM. Global cancer statistics in the year 2000. Lancet Oncol. 2001; 2:533-543.

3. Fry WA, Phillips JL, Menck HR. Ten-year survey of lung cancer treatment and survival in hospitals in the United States - A National Cancer Data Base report. Cancer. 1999; 86:1867-1876.

4. Holdenrieder S, Von Pawel J, Duell T, Feldmann K, Raith H, Schollen A, Nagel D, Stieber P. Clinical relevance of thymidine kinase for the diagnosis, therapy monitoring and prognosis of non-operable lung cancer. Anticancer Res. 2010; 30:1855-1862.

5. Wang L, Wang D, Zheng G, Yang Y, Du L, Dong Z, Zhang X, Wang C. Clinical evaluation and therapeutic monitoring value of serum tumor markers in lung cancer. Int J Biol Markers. 2016; 31:e80-87.

6. Wang B, He YJ, Tian YX, Yang RN, Zhu YR, Qiu H. Clinical utility of haptoglobin in combination with CEA, NSE and CYFRA21-1 for diagnosis of lung cancer. Asian Pac J Cancer Prev. 2014; 15:9611-9614.

7. Wang WJ, Tao Z, Gu W, Sun LH. Clinical observations on the association between diagnosis of lung cancer and serum tumor markers in combination. Asian Pac J Cancer Prev. 2013; 14:4369-4371.

8. Lu H, Ouyang W, Huang C. Inflammation, a key event in cancer development. Mol Cancer Res. 2006; 4:221-233.

9. Grivennikov SI, Greten FR, Karin M. Immunity, Inflammation, and Cancer. Cell. 2010; 140:883-899.

10. Schultz DR, Arnold PI. Properties of four acute phase proteins: C-reactive protein, serum amyloid a protein, $\alpha 1-$ acid glycoprotein, and fibrinogen. Semin Arthritis Rheum. 1990; 20:129-147.

11. Yuki M, Machida N, Sawano T, Itoh H. Investigation of serum concentrations and immunohistochemical localization of $\alpha 1$-acid glycoprotein in tumor dogs. Vet Res Commun. 2011; 35:1-11.
12. Pierce BL, Ballard-Barbash R, Bernstein L, Baumgartner RN, Neuhouser ML, Wener MH, Baumgartner KB, Gilliland FD, Sorensen BE, Mctiernan A. Elevated biomarkers of inflammation are associated with reduced survival among breast cancer patients. J Clin Oncol. 2009; 27:3437-3444.

13. Cho WC, Yip TT, Cheng WW, Au JS. Serum amyloid A is elevated in the serum of lung cancer patients with poor prognosis. Br J Cancer. 2010; 102:1731-1735.

14. Cocco E, Bellone S, Karim El-Sahwi MD, Cargnelutti M, Natalia Buza MD, Tavassoli FA, Schwartz PE, Rutherford TJ, Sergio Pecorelli MD and $\uparrow$ ADSM. Serum amyloid A. Cancer. 2010; 116:843-851.

15. Kaneti J, Winikoff Y, Zimlichman S, ShainkinKestenbaum R. Importance of serum amyloid A (SAA) level in monitoring disease activity and response to therapy in patients with prostate cancer. Urol Res. 1984; 12:239-241.

16. Glojnarić I, Casl MT, Simić D, Lukac J. Serum amyloid A protein (SAA) in colorectal carcinoma. Clin Chem Lab Med. 2001; 39:129-133.

17. Chan DC, Chen CJ, Chu HC, Chang WK, Yu JC, Chen YJ, Wen LL, Huang SC, Ku CH, Liu YC. Evaluation of Serum Amyloid A as a Biomarker for Gastric Cancer. Ann Surg Oncol. 2007; 14:84-93.

18. Heikkilä K, Ebrahim S, Lawlor and A D. A systemic review of the association between circulating concentrations of $\mathrm{C}$ reactive protein and cancer. J Epidemiol Community Health. 2007; 61:824-833.

19. Jing X, Huang C, Zhou H, Li C, Fan L, Chen J, Zhang G, Liu Y, Cui Z, Qi D. Association between serum C-reactive protein value and prognosis of patients with non-small cell lung cancer: a meta-analysis. Int J Clin Exp Med. 2015; 8:10633-10639.

20. Leuzzi G, Galeone C, Gisabella M, Duranti L, Taverna F, Suatoni P, Morelli D, Pastorino U. Baseline C-reactive protein level predicts survival of early-stage lung cancer: evidence from a systematic review and meta-analysis. Tumori. 2016:0.

21. Wu CY, Wu MS, Chiang EP, Wu CC, Chen YJ, Chen CJ, Chi NH, Chen GH, Lin JT. Elevated plasma osteopontin associated with gastric cancer development, invasion and survival. Gut. 2007; 56:782-789.

22. Gong M, Lu Z, Fang G, Bi J, Xue X. A small interfering RNA targeting osteopontin as gastric cancer therapeutics. Cancer Lett. 2008; 272:148-159.

23. Fedarko NS, Jain A, Karadag A, Van Eman MR, Fisher LW. Elevated serum bone sialoprotein and osteopontin in colon, breast, prostate, and lung cancer. Clin Cancer Res. 2001; 7:4060-4066.

24. Scatena M, Liaw L, Giachelli CM. Osteopontin: a multifunctional molecule regulating chronic inflammation and vascular disease. Arterioscler Thromb Vasc Biol. 2007; 27:2302-2309.

25. Peng B, Wang YH, Huang Z, Feng SJ, Wang YS. Prognostic significance of osteopontin in patients with lung cancer: a meta-analysis. Int J Clin Exp Med. 2014; 7:4616-4626. 
26. Carvalho S, Troost EG, Bons J, Menheere P, Lambin P, Oberije C. Prognostic value of blood-biomarkers related to hypoxia, inflammation, immune response and tumour load in non-small cell lung cancer-A survival model with external validation. Radiother Oncol. 2016.

27. Wai PY, Kuo PC. The role of Osteopontin in tumor metastasis. J Surg Res. 2004; 121:228-241.

28. Nolen BM, Langmead CJ, Choi S, Lomakin A, Marrangoni A, Bigbee WL, Weissfeld JL, Wilson DO, Dacic S, Siegfried JM, Lokshin AE. Serum biomarker profiles as diagnostic tools in lung cancer. Cancer Biomark. 2011; 10:3-12.

29. Ma S, Wang W, Xia B, Zhang S, Yuan H, Jiang H, Meng W, Zheng X, Wang X. Multiplexed Serum Biomarkers for the Detection of Lung Cancer. EBioMedicine. 2016; 11:210-218.

30. Takahashi N, Furuta K, Taniguchi H, Sasaki Y, Shoji H, Honma Y, Iwasa S, Okita N, Takashima A, Kato K, Hamaguchi T, Shimada Y, Yamada Y. Serum level of hepatocyte growth factor is a novel marker of predicting the outcome and resistance to the treatment with trastuzumab in HER2-positive patients with metastatic gastric cancer. Oncotarget. 2016; 7:4925-4938. doi: 10.18632/oncotarget.6753.

31. Canadas I, Taus A, Gonzalez I, Villanueva X, Gimeno J, Pijuan L, Domine M, Sanchez-Font A, Vollmer I, Menendez S, Arpi O, Mojal S, Rojo F, et al. High circulating hepatocyte growth factor levels associate with epithelial to mesenchymal transition and poor outcome in small cell lung cancer patients. Oncotarget. 2014; 5:5246-5256. doi: 10.18632/ oncotarget. 2124.

32. Arrieta O, Cruz-Rico G, Soto-Perez-de-Celis E, RamirezTirado LA, Caballe-Perez E, Martinez-Hernandez JN, MartinezAlvarez I, Soca-Chafre G, Macedo-Perez EO, Astudillo-de la Vega H. Reduction in Hepatocyte Growth Factor Serum Levels is Associated with Improved Prognosis in Advanced Lung Adenocarcinoma Patients Treated with Afatinib: a Phase II Trial. Target Oncol. 2016; 11:619-629.

33. Naumnik W, Naumnik B, Niklinska W, Ossolinska M, Chyczewska E. Clinical Implications of Hepatocyte Growth Factor, Interleukin-20, and Interleukin-22 in Serum and Bronchoalveolar Fluid of Patients with Non-Small Cell Lung Cancer. Adv Exp Med Biol. 2016; 952:41-49.

34. Zhou F, Chen J, Tao G, Zhu M, Xie W, Cao X. Increased levels of exhaled sICAM1, sVCAM1, and sE-selectin in patients with non-small cell lung cancer. Respir Med. 2014; 108:1670-1676.

35. Gogali A, Charalabopoulos K, Zampira I, Konstantinidis AK, Tachmazoglou F, Daskalopoulos G, Constantopoulos SH, Dalavanga Y. Soluble adhesion molecules E-cadherin, intercellular adhesion molecule-1, and E-selectin as lung cancer biomarkers. Chest. 2010; 138:1173-1179.

36. Wang J, Ma R, Sharma A, He M, Xue J, Wu J, Dun B, Li G, Wang X, Ji M, She JX, Tang J. Inflammatory serum proteins are severely altered in metastatic gastric adenocarcinoma patients from the Chinese population. PLoS One. 2015; 10:e0123985.
37. Li X, Lu J, Ren H, Chen T, Gao L, Di L, Song Z, Zhang Y, Yang T, Thakur A, Zhou SF, Yin Y, Chen M. Combining multiple serum biomarkers in tumor diagnosis: A clinical assessment. Mol Clin Oncol. 2013; 1:153-160.

38. Li X, Asmitananda T, Gao L, Gai D, Song Z, Zhang Y, Ren H, Yang T, Chen T, Chen M. Biomarkers in the lung cancer diagnosis: a clinical perspective. Neoplasma. 2012; 59:500-507.

39. Ludwig JA, Weinstein JN. Biomarkers in cancer staging, prognosis and treatment selection. Nat Rev Cancer. 2005; 5:845-856.

40. Topalian SL, Taube JM, Anders RA, Pardoll DM. Mechanismdriven biomarkers to guide immune checkpoint blockade in cancer therapy. Nat Rev Cancer. 2016; 16:275-287.

41. Syn NL, Yong WP, Goh BC, Lee SC. Evolving landscape of tumor molecular profiling for personalized cancer therapy: a comprehensive review. Expert Opin Drug Metab Toxicol. 2016:1-12.

42. Holdenrieder S, Stieber P, Von Pawel J, Raith H, Nagel D, Feldmann K, Seidel D. Early and Specific Prediction of the Therapeutic Efficacy in Non\&ndash;Small Cell Lung Cancer Patients by Nucleosomal DNA and Cytokeratin-19 Fragments. Ann N Y Acad Sci. 2006; 1075:244-257.

43. Vollmer RT, Govindan RGraziano SL, Gamble G, Garst J, Kelley MJ, Christenson RH. Serum CYFRA 21-1 in Advanced Stage Non-Small Cell Lung Cancer: An Early Measure of Response. Clin Cancer Res. 2003; 9:1728-1733.

44. Holdenrieder S, Stieber P, von Pawel J, Raith H, Nagel D, Feldmann K, Seidel D. Circulating nucleosomes predict the response to chemotherapy in patients with advanced nonsmall cell lung cancer. Clin Cancer Res. 2004; 10:5981-5987.

45. Ettinger DS, Bepler G, Bueno R, Chang A, Chang JY, Chirieac LR, D'Amico TA, Demmy TL, Feigenberg SJ Jr GF. Non-small cell lung cancer clinical practice guidelines in oncology. J Natl Compr Canc Netw. 2006; 4:94-123.

46. Ahn JM, Cho JY. Current Serum Lung Cancer Biomarkers. J Mol Biomark Diagn. 2013.

47. Sung HJ, Ahn JM, Yoon YH, Rhim TY, Park CS, Park JY, Lee SY, Kim JW, Cho JY. Identification and validation of SAA as a potential lung cancer biomarker and its involvement in metastatic pathogenesis of lung cancer. J Proteome Res. 2011; 10:1383-1395.

48. Milan E, Lazzari C, Anand S, Floriani I, Torri V, Sorlini C, Gregorc V, Bachi A. SAA1 is over-expressed in plasma of non small cell lung cancer patients with poor outcome after treatment with epidermal growth factor receptor tyrosinekinase inhibitors. J Proteomics. 2012; 76:91-101.

49. Nozoe T, Korenaga D, Futatsugi M, Saeki H, Maehara Y, Sugimachi K. Immunohistochemical expression of C-reactive protein in squamous cell carcinoma of the esophagussignificance as a tumor marker. Cancer Lett. 2003; 192:89-95.

50. Holdenrieder S, Von PJT, Feldmann K, Raith H, Schollen A, Nagel D, Stieber P. Clinical relevance of thymidine kinase for the diagnosis, therapy monitoring and prognosis of nonoperable lung cancer. Anticancer Res. 2010; 30:1855-1862. 